\title{
Frequency-dependent selection at the diazinon resistance locus of the Australian sheep blowfly, Lucilia cuprina
}

\author{
J. A. McKenzie, J. C. Fegent \\ and $\mathrm{G}$. Weller
}

Department of Genetics, University of Melbourne, Parkville, Victoria 3052, Australia.

The egg to adult viability of susceptibles (SS) at the diazinon resistance locus of $L$. cuprina was facilitated by RS in mixed $(1: 1)$ cultures at diazinon concentrations greater than $0 \cdot 0002$ per cent $(W / V)$ in the concentration range 0-0.00053 per cent (W/V). SS survived in mixed culture at concentrations lethal to pure cultures of this genotype. The egg to adult viability of RS was not influenced by the presence of SS.

Trials at 0 per cent and 0.0002 per cent $(\mathrm{W} / \mathrm{V})$ diazinon showed the viability of both genotypes decreased in the presence of diazinon and with increasing density. Viability of RS was independent of its frequency in mixed culture but SS viability was enhanced at frequencies $\leqq 20$ per cent at the 0.0002 per cent $(W / V)$ concentration. There was no indication of density $x$ frequency interaction.

\section{INTRODUCTION}

Wallace (1968) represents soft selection as the process where, for example, the level of mortality remains constant in spite of fluctuations in the fitness distributions of a population of genotypes. Strictly defined, soft selection must include the interaction of density-and frequency-dependent factors (Wallace, 1975). It allows for the possibility of subtle ecological interactions between genotypes which may be critical to evolutionary processes (Ayala and Campbell, 1974; Clarke, 1979; Parsons, 1983; Emlen, 1985).

Models of the evolution of insecticide resistance are usually based on the assumption of hard selection, fixed fitness sets defined by the presence, or absence, of the insecticide (Georghiou and Taylor, 1976; Comins, 1979; Mani, 1985). However, recent studies in L. cuprina have shown specific fitness differences may occur at concentrations that are sub-lethal for each genotype (McKenzie and Whitten, 1982; 1984) questioning both the tenet of fixed fitness sets and the assumption that fitness is determined only by concentration thresholds about which mortality is genotypically dependent (Brown and Pal, 1971). That is, they suggest that the evolution of insecticide resistance may involve soft, rather than hard, selective processes in some circumstances (Whitten and McKenzie, 1982).
McKenzie et al., (1980) have described resistance of $L$. cuprina to the organophosphorus insecticide diazinon in terms of allelic substitution of the $R_{1 A}$ allele for the susceptible (S) allele of the Rop-1 locus on chromosome 4 (Foster et al., 1981). In sheep-grazing areas of Australia susceptible flies are currently rare (McKenzie et al., 1980; Hughes, 1981; McKenzie, 1984). Selection for insecticide resistance is concentrated at the larval stage of the life cycle (Whitten et al., 1980).

Comparison of the relative viabilities of larval genotypes in artificial myiases on sheep has shown heterozygotes and SS homozygotes to be similar for some 20 weeks post-treatment of sheep, several weeks beyond the protection period afforded by diazinon. During this period resistant (RR) homozygotes are at a selective advantage in spite of a considerable decay in insecticide concentration on the sheep (McKenzie and Whitten, 1982). Thus, resistance is recessive, with respect to viability, for a significant period. Such a fitness relationship may lower the rate of the evolution of resistance (Curtis, 1981; Wood and Mani, 1981; McKenzie 1983). A critical period is when the $R$ allele is rare in the population, fitness comparisons being between SS and RS genotypes (Whitten and McKenzie, 1982).

The similar viabilities of these genotypes at the Rop-1 locus over a large diazinon concentration range suggests different selective interactions may 
occur within that range. The influence of the density and frequency of the genotypes in these interactions is considered in the laboratory experiments described in this paper.

\section{MATERIALS AND METHODS}

Experiments were conducted at $27^{\circ} \mathrm{C}$ in constant light. Media for larval development were placed in $110 \mathrm{ml}$ cups. The base medium consisted of $52.5 \mathrm{gm}$ of Hortico meat and bone meal per cup into which $0.1 \mathrm{gm}$ of cotton linters were blended with $75 \mathrm{ml}$ of distilled water. For media containing insecticide appropriate volumes from a stock solution $(0.01$ per cent $(\mathrm{W} / \mathrm{V})$ diazinon jetting formulation mixed in water) were mixed with water to yield a final volume of $75 \mathrm{ml}$ for blending. An overall concentration range of 0 to 0.003 per cent $(\mathrm{W} / \mathrm{V})$ diazinon was produced in the media.

Initial tests showed no mortality differences between field derived and standard laboratory susceptible strains (SWT and LBB) so the latter were used. Heterozygotes were produced by crossing susceptibles to $R_{1 A}$ homozygotes of a strain derived from a field collection near Lockington, Victoria.

In all experiments the proportion of eggs of a particular genotype that, after larval and pupal development, reached the adult stage was measured. Eggs were placed on the medium in combinations appropriate for a specific experiment (see below) and after larval development pupation occurred in vermiculite. Sugar and water were available to emerging adults.

The genotype of files emerging in mixed culture experiments was ascertained by treating 2-day-old adults with a dose to discriminate SS from RS $(0.5 \mathrm{u} / \mathrm{l}$ of 0.01 per cent $(\mathrm{V} / \mathrm{V})$ mixed in deodorised kerosene; diazinon delivered to the thorax of the fly by Drummond micro-pipette) (McKenzie et al., 1980).

\section{Dosage Mortality Curves}

Two hundred eggs of SS, RS or RR were placed in pure culture on media covering the diazinon concentration range. Five trials were conducted for each genotype.

\section{Pure and Mixed Cultures}

Two hundred SS or RS eggs were placed on media in the diazinon concentration range of $0-0.0004$ per cent $(\mathrm{W} / \mathrm{V})$ (where SWT was source of S allele) or $0-0.00053$ per cent $(\mathrm{W} / \mathrm{V})(\mathrm{LBB})$ in pure culture experiments. One hundred eggs of each genotype were used in the mixed culture experiments over the same concentration range. Twelve trials were conducted for the SWT experiments, eight for those involving LBB.

\section{Frequency and Density Experiments}

In a first experiment measures were made for SS/RS comparison at 0 per cent and 0.0002 per cent $(\mathrm{W} / \mathrm{V})$ diazinon at densities of 100,200 and 500 eggs per cup and at frequencies of SS and RS genotypes of $20,40,60,80$ and 100 per cent. Six measures were made for each genotype at each frequency and density.

A second experiment used 200 eggs per cup at both diazinon concentrations. Ten trials were conducted at SS frequencies of 10, 20, 30 and 40 per cent in mixed SS/RS cultures.

\section{RESULTS \\ Dosage Mortality Curves}

The dosage mortality curves are presented in fig. 1 . There is a natural mortality in egg hatch and development that is independent of insecticide presence. The egg hatch percentage is similar for all genotypes (RR, 77.7 $\pm 1 \cdot 21$ (standard error in angular scale); $\operatorname{RS} 80 \cdot 7 \pm 4 \cdot 15$; SS $78 \cdot 0 \pm 2 \cdot 33$ ) but RS may have a higher overall developmental percentage in the absence of the insecticide (table 1). The dosage mortality curves are therefore for the range of insecticide concentrations over which there is a linear increase over inherent mortality. The data indicated the inheritance of resistance to be partially dominant, although clearly there is some overlap between the viability distributions of the genotypes in the concentration range considered.

\section{Pure and Mixed Culture Experiments}

RS had a greater emergence percentage than SS at 0 per cent $(\mathrm{W} / \mathrm{V})$ diazinon when SWT was the susceptible strain. However, similar trends (fig. 2) were observed for each trial irrespective of whether SWT or LBB was used as the susceptible strain in SS (standard error range in angular scale, SWT, pure $1 \cdot 23-1 \cdot 82$, mixed $1 \cdot 28-2 \cdot 43$; LBB, pure $0 \cdot 0$ $2 \cdot 71$, mixed $1 \cdot 27-3.95)$ and RS (RR $\times$ SWT pure 1.46-2.99, mixed 2.64-3.85; RR $\times$ LBB, pure 3.07$6 \cdot 09$, mixed $1 \cdot 49-4 \cdot 40$ ) comparisons. As expected from the dosage mortality curves (fig. 1) RS has a 


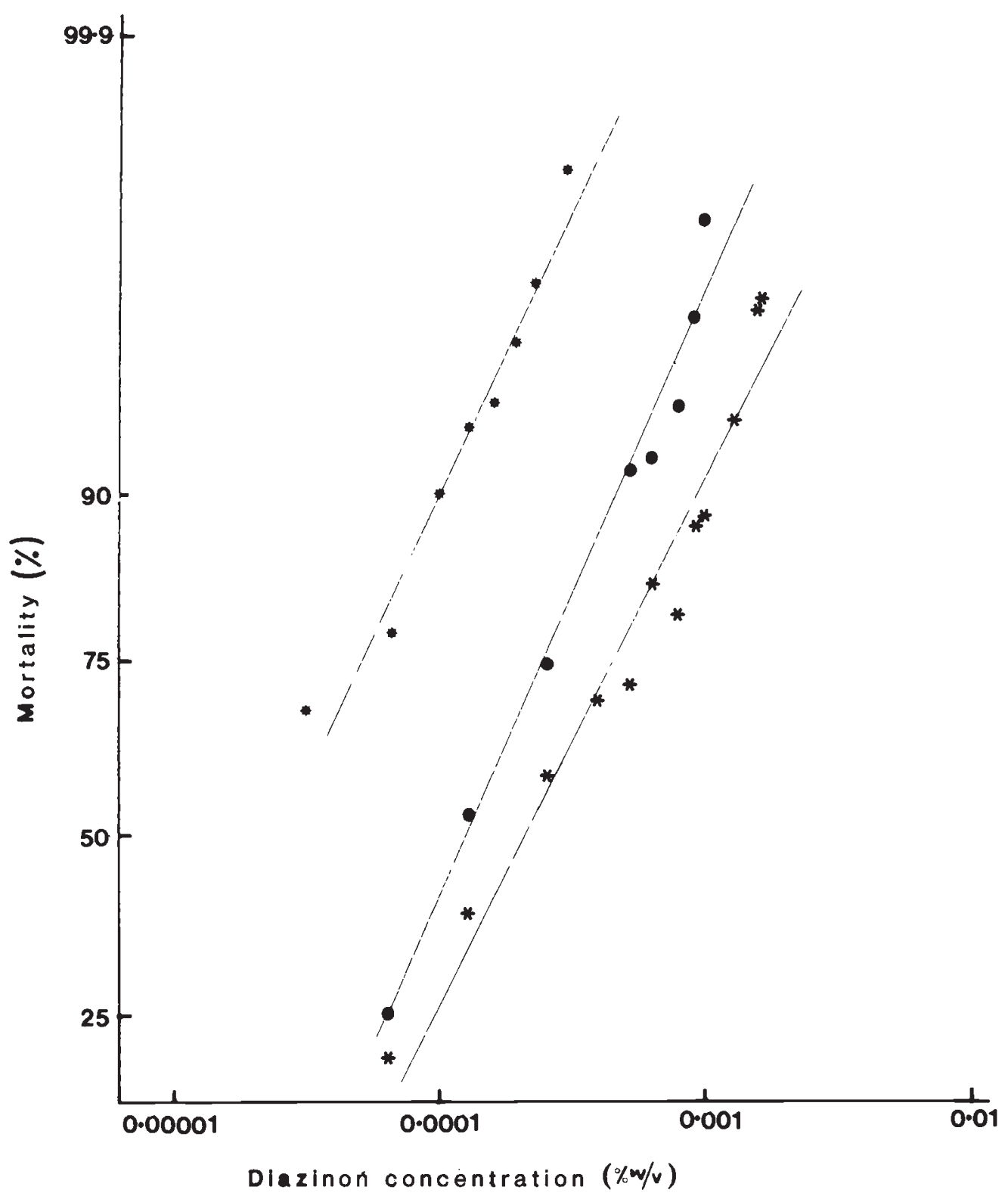

Figure 1 Dosage mortality curves for SS $(\star)$, RS $(0)$ and RR $(*)$ genotypes exposed to diazinon during development from egg to adult.

higher survivorship than SS with increasing diazinon concentration.

The percentage emergence of SS adults from mixed culture was significantly greater than that from pure culture at concentrations greater than 0.0002 per cent (W/V) diazinon (fig. 2). While differences in the percentage of RS adults emerging from pure or mixed culture were apparent, particularly for the LBB experiments (fig. 2), these were not significant at any concentration as there was considerable variance for each estimate (see above).

\section{Frequency and Density Experiments}

Experiment 1 The results are presented in table 1. SS and RS data are analysed separately as at 0.0002 per cent $(\mathrm{W} / \mathrm{V})$ diazinon there was an obvious difference in the proportion of each genotype expected to reach the adult stage (fig. 1) and 
Table 1 Mean $(\bar{x})$ percentage (over 6 measures), relative to initial genotypic frequency, of SS and RS adults emerging after development from 100, 200 and 500 eggs per cup of 0 per cent and 0.0002 per cent (W/V) diazinon supplemented media. Standard errors (S.E.) are in angular scale

\begin{tabular}{|c|c|c|c|c|c|c|c|c|c|c|c|c|}
\hline \multirow[b]{3}{*}{ Density: } & \multicolumn{12}{|c|}{ SS } \\
\hline & \multicolumn{6}{|c|}{$0 \%$} & \multicolumn{6}{|c|}{$0.0002 \%$} \\
\hline & & 100 & & 200 & & 500 & & 100 & & 200 & & 500 \\
\hline Frequency & $\bar{x}$ & S.E. & $\bar{x}$ & S.E. & $\bar{x}$ & S.E. & $\bar{x}$ & S.E. & $\overline{\mathbf{x}}$ & S.E. & $\vec{x}$ & S.E. \\
\hline 20 & $50 \cdot 0$ & $3 \cdot 9$ & $44 \cdot 1$ & $4 \cdot 5$ & $51 \cdot 0$ & $3 \cdot 4$ & $21 \cdot 8$ & $2 \cdot 8$ & $14 \cdot 8$ & $1 \cdot 3$ & $11 \cdot 0$ & $3 \cdot 4$ \\
\hline 40 & $44 \cdot 6$ & $3 \cdot 2$ & $34 \cdot 8$ & $3 \cdot 7$ & $41 \cdot 4$ & $3 \cdot 5$ & $10 \cdot 2$ & 1.9 & $4 \cdot 8$ & 1.7 & $4 \cdot 9$ & $2 \cdot 9$ \\
\hline 100 & $50 \cdot 0$ & $4 \cdot 7$ & $37 \cdot 4$ & $5 \cdot 3$ & $37 \cdot 4$ & $3 \cdot 7$ & $8 \cdot 6$ & $2 \cdot 7$ & $4 \cdot 8$ & 1.8 & $2 \cdot 4$ & $2 \cdot 1$ \\
\hline
\end{tabular}

\begin{tabular}{|c|c|c|c|c|c|c|c|c|c|c|c|}
\hline & & & & & & R & & & & & \\
\hline & & & $0 \%$ & & & & & & $02 \%$ & & \\
\hline & 100 & & 200 & & 500 & & 100 & & 200 & & 00 \\
\hline$\dot{x}$ & S.E. & $\bar{x}$ & S.E. & $\overline{\boldsymbol{x}}$ & S.E. & $\bar{x}$ & S.E. & $\bar{x}$ & S.E. & $\bar{x}$ & S.E. \\
\hline $58 \cdot 2$ & 3.6 & $55 \cdot 3$ & $5 \cdot 2$ & $49 \cdot 1$ & $5 \cdot 3$ & $53 \cdot 7$ & 6.9 & $45 \cdot 3$ & $4 \cdot 2$ & $43 \cdot 5$ & $5 \cdot 0$ \\
\hline $56 \cdot 8$ & $4 \cdot 6$ & $49 \cdot 1$ & $2 \cdot 0$ & $51 \cdot 1$ & $5 \cdot 1$ & $52 \cdot 6$ & $3 \cdot 1$ & $52 \cdot 8$ & $4 \cdot 1$ & $38 \cdot 1$ & $2 \cdot 3$ \\
\hline $52 \cdot 6$ & $3 \cdot 3$ & 39.8 & $3 \cdot 1$ & 51.7 & $3 \cdot 3$ & 48.8 & $2 \cdot 4$ & $42 \cdot 8$ & $5 \cdot 4$ & $31 \cdot 2$ & $3 \cdot 0$ \\
\hline
\end{tabular}

because there was a general tendency for the heterozygote to display higher viability under control conditions (table 1).

The initial analyses of variance (table 2) showed insecticide concentration and culture density to significantly influence the viability of both genotypes. The percentage reaching the adult stage decreased in the presence of diazinon and there was some tendency for decreasing emergence with increasing density, particularly at 0.0002 per cent $(\mathrm{W} / \mathrm{V})$ diazinon. The frequency of the genotype significantly influenced viability only for the SS genotype. In all cases interactive effects were insignificant.

Analyses of variance within an insecticide concentration (table 2) indicated insignificant density and frequency effects at 0 per cent $(\mathrm{W} / \mathrm{V})$ diazinon for each genotype. Both genotypes' viability was influenced by culture density at 0.0002 per cent (W/V) diazinon but only SS viability was influenced by the frequency of the genotype in culture at this concentration. Genotype $\mathrm{X}$ frequency interactions were insignificant for each genotype and concentration comparison.

Least significance difference comparison showed SS adult emergence from cultures in which eggs had an initial SS frequency of 20 per cent to be significantly $(P<0 \cdot 001)$ increased relative to the values of all other starting frequencies which did not differ significantly from each other.
Experiment 2 The results (table 3 ) and analyses (Table 4) confirmed the results of experiment 1. In the range of initial SS frequencies of 10-40 per cent in mixed culture there was not a significant frequency effect on viability in the absence of diazinon in the medium although the proportion of adults emerging did vary between trials. However, at 0.0002 per cent $(\mathrm{W} / \mathrm{V})$ diazinon SS viability was significantly influenced by the frequency of the SS genotype in culture. Adults percentage emergence of the SS genotype from mixed cultures in which SS eggs had a frequency of 10 per cent was significantly $(P<0 \cdot 001)$ greater than the values at other frequencies. Percentage emergence of SS genotypes from 20 per cent cultures was greater than from 30 per cent $(P<0 \cdot 001)$ and 40 per cent $(P<0.01)$ cultures which did not differ significantly from each other.

Taken as a whole the data of the two experiments showed the viability of SS genotypes was enhanced in mixed SS/RS cultures at 0.0002 per cent $(\mathrm{W} / \mathrm{V})$ diazinon concentration when the initial frequency of SS eggs starting those cultures is equal to, or less than, 20 per cent.

\section{DISCUSSION}

The dosage mortality curves derived using the meat meal test system provided results similar to those 


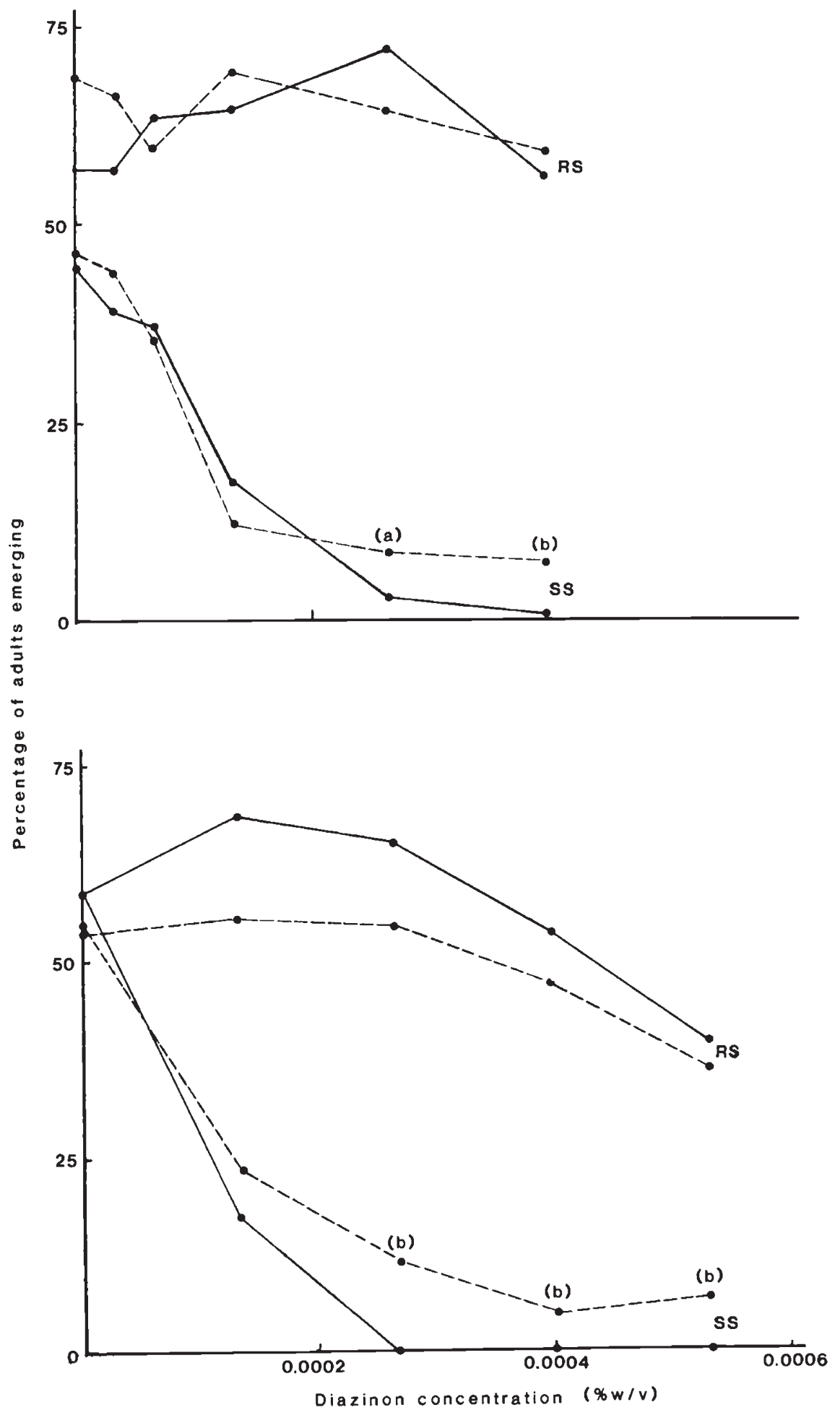

Figure 2 Percentage of adults emerging from pure (solid line) and mixed (broken line) cultures of SS and RS genotypes. SWT is the SS strain in the upper graph, LBB in the lower. RS in generated by the cross of the strain with RR. (a) significant $(P<0.01)$ difference between emergence from pure and mixed culture, (b) $P<0.001$. 
Table 2 Analyses of variance of SS and RS emergence of adults after development from 100,200 and 500 eggs at genotypic frequencies of $20,40,60,80$ and 100 per cent on 0 per cent and 0.0002 per cent $(\mathrm{W} / \mathrm{V})$ diazinon supplemented media. Subsequent analysis is within each concentration

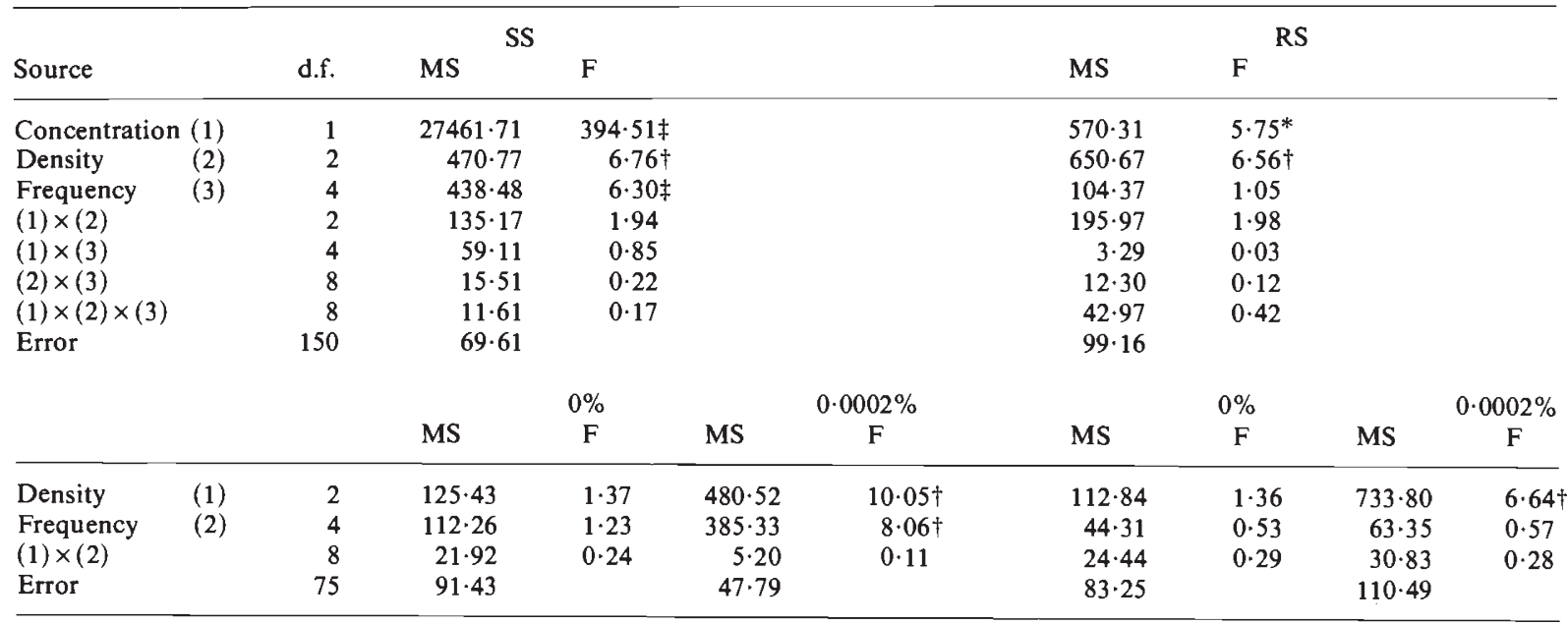

${ }^{*} P<0.05$

$\dagger P<0.01$

$\ddagger P<0.001$

Table 3 Mean ( \pm S.E. in angles) Percentage (over 10 replicates) of SS eggs, relative to initial genotypic frequency in a SS/RS mixed culture, reaching the adult stage after development on 0 per cent and 0.0002 per cent $(\mathrm{W} / \mathrm{V})$ diazinon supplemented media at a density of 200 eggs per cup

Frequency of SS eggs

\begin{tabular}{llr} 
in SS/RS mixed culture & $0 \cdot 0 \%$ & $0.0002 \%$ \\
\hline 10 & $53 \cdot 9 \pm 2 \cdot 74$ & $25 \cdot 7 \pm 2 \cdot 19$ \\
20 & $54 \cdot 8 \pm 4 \cdot 10$ & $12 \cdot 4 \pm 1 \cdot 66$ \\
30 & $44 \cdot 4 \pm 2 \cdot 81$ & $4 \cdot 3 \pm 1 \cdot 29$ \\
40 & $45 \cdot 5 \pm 2 \cdot 36$ & $4 \cdot 6 \pm 0 \cdot 94$ \\
\hline
\end{tabular}

observed in other tests in Lucilia (Roxburgh and Shanahan, 1973; Arnold and Whitten, 1975) and in insects generally (Brown and Pal, 1971) in that resistance displayed a partially dominant mode of inheritance (fig. 1). It should be noted that the RS probit line may be partly displaced towards the RR line as the overall viability of the heterozygote is greater in these experiments. This is almost certainly due to general heterotic effects that are not specifically related to the diazinon resistance locus as similar viability has been observed for all three genotypes in the absence of the insecticide when a common genetic background is shared (McKenzie et al., 1982; McKenzie and Whitten, 1984).

The distribution represented by the dosage mortality curves indicated that there is some over- lap between the viabilities of the genotypes which allows the potential for subtle genotypic interactions to occur in the presence of diazinon. This potential is realised in the comparison of SS and $\mathrm{RS}$ genotypes in these experiments.

The viability of SS was facilitated, relative to that in pure culture, in mixed RS/SS cultures at diazinon concentrations greater than 0.0002 per cent (W/V) (fig. 2). The presence of SS has no effect on the viability of RS over the concentration range considered. Similar results were observed for SS and RS when different susceptible strains (SWT and LBB) were used so it seems the facilitation effect may be associated directly with the resistance locus.

The interaction between SS and RS genotypes was further investigated in experiments conducted over a range of culture densities and genotypic frequencies in media at 0 per cent and 0.0002 per cent $(\mathrm{W} / \mathrm{V})$ diazinon concentrations. The latter was chosen as some SS individuals were viable in pure culture at this concentration (figs. 1 and 2) and thus sub-lethal effects could be considered. Pragmatically, this concentration also allowed sufficient SS genotypes to reach the adult stage to enable comparison of any interactive effects.

The initial experiment demonstrated that viability was influenced by culture concentration and density for both genotypes. Viability was lowered by insecticide presence and increasing density. (tables 1 and 2). Importantly, the viability of the 
Table 4 Analyses of variance of percentage of SS genotypes reaching the adult stage after development of an 0 per cent and 0.0002 per cent (W/V) Diazinon supplemented media starting egg frequencies of 10, 20,30 and 40 per cent in mixed SS/RS cultures

\begin{tabular}{|c|c|c|c|c|c|c|c|}
\hline \multirow[b]{2}{*}{ Source } & \multirow[b]{2}{*}{ d.f. } & \multirow[b]{2}{*}{ MS } & \multirow[b]{2}{*}{$\mathrm{F}$} & & \multicolumn{3}{|c|}{ Within Concentration Analysis } \\
\hline & & & & & d.f. & MS & $\mathbf{F}$ \\
\hline Concentration (1) & 1 & 13471.68 & $343.93 \ddagger$ & Frequency & 3 & $99 \cdot 21$ & $2 \cdot 13$ \\
\hline Frequency (2) & 3 & 663.03 & $16.93 \ddagger$ & Trial & 9 & $237 \cdot 67$ & $5 \cdot 10 \ddagger$ \\
\hline Trial (3) & 9 & $131 \cdot 42$ & $3 \cdot 36 \dagger$ & Error & 27 & $46 \cdot 56$ & \\
\hline (1) $\times(2)$ & 3 & $194 \cdot 29$ & $4.96 \dagger$ & & & & \\
\hline (1) $\times(3)$ & 9 & $123 \cdot 25$ & $3 \cdot 15 \dagger$ & & & $0.0002 \%$ & \\
\hline (2) $\times(3)$ & 27 & $35 \cdot 33$ & 0.90 & Frequency & 3 & $758 \cdot 11$ & $27 \cdot 14 \ddagger$ \\
\hline Error & 27 & $39 \cdot 17$ & & Trial & 9 & 16.99 & 0.61 \\
\hline & & & & Error & 27 & $27 \cdot 93$ & \\
\hline
\end{tabular}

$\dagger P<0.01$

$\ddagger P<0.001$

SS genotype was frequency-dependent at 0.0002 per cent $(\mathrm{W} / \mathrm{V})$ diazinon but not in the absence of the insecticide. At an initial frequency of 20 per cent in a mix of SS and RS eggs the viability of SS was enhanced, relative to viabilities at higher SS frequencies, at 0.0002 per cent $(\mathrm{W} / \mathrm{V})$ diazinon. The relative viability of RS was independent of genotype frequency and there was no indication of interaction between frequency and the density of the culture for either genotype. That is, while density influenced the proportion of a genotype reaching the adult stage, similar trends were observed at each density.

Frequency-dependent selection of SS genotypes was confirmed by comparison of viability over a more limited range of initial SS frequency (10-40 per cent) in mix ed culture at a fixed density of 200 eggs per cup. The results showed that the SS genotype has a relatively greater viability when present at frequencies of 20 per cent, or less, in mixed SS/RS cultures compared to viabilities at frequencies greater than this (tables 3 and 4). Viability was significantly greater at a frequency of 10 per cent than at 20 per cent. This may suggest an inverse relationship between SS frequency and viability. Caution should be exercised with respect to this relationship as random mortality at low genotypic frequencies may over estimate viability values. However, the observation of frequency dependency in both experiments and the similarity of the number of adults emerging from 0.0002 per cent $(\mathrm{W} / \mathrm{V})$ diazinon medium in each (tables 1 and 3) allows confidence in the demonstration of the phenomenon.

It should be noted that the present results do not provide an explanation for the recessiveness of resistance, with respect to viability, observed in egg implant studies on sheep over a considerable concentration range (McKenzie and Whitten,
1982; 1984). Irrespective of the facilitation of SS, the RS genotype was significantly more viable in the presence of diazinon. It is possible that the laboratory test system involves different genotypic interactions to those observed in implants on sheep. However, preliminary observations indicate facilitation of SS to occur in implants. The interactions may be more complex when SS, RS and RR genotypes are present, the experimental conditions of the initial implant trials, as differences have been observed with the number of genotypes compared in other systems (Tos̄ić and Ayala, 1981). Further work is required to resolve this.

Comparison of the mixed culture and frequency and density experiments indicates critical interaction frequencies may vary with the insecticide concentration. A general association between the level of stress, genotypic interaction and the definition of fitness relationships has several consequences for models of the maintenance of genetic variability (Wallace, 1968; Parsons, 1971) and for the framework in which the evolution of insecticide resistance may be considered (Whitten and McKenzie, 1982).

Not least of these is that fitness sets may not be fixed, a characteristic contrary to many models of the evolution of resistance (McKenzie, 1983). In this instance the genotypic interaction is unlikely to greatly influence the rate of the development of resistance as RS genotypes would be at significant frequencies before the interaction could come into play. However, the acceptance of the possibility of interactions that move in the direction of a soft selective mode enables consideration of the evolution of resistance without the usual requirement of a decrease in population numbers.

The system may also allow a mechanistic analysis of the process of frequency-dependent selection. It may be possible to describe an association 
between the selective agent, the phenotypes and the physiological and biochemical properties related to those phenotypes (Clarke 1975) as there are some data on the biochemical basis of diazinon resistance in L. cuprina (Hughes and Devonshire, 1982). Similar opportunities have been effectively utilised in other systems (Haj-Ahmad and Hickey, 1982) but there is no general consensus on the molecular bases of these interactions as they relate to the maintenance of genetic variability, particularly if there is the inference of the "conditioning" of the larval environment of one genotype by another (Huang et al., 1971; Dolan and Robertson, 1975). The diazinon resistance system of $L$. cuprina may have a contribution to make in this area as SS genotypes are facilitated in diazinon containing media previously conditioned by RS (or RR) larvae (McKenzie, unpublished).

Acknowledgements The technical assistance of Julie Lycette and Nan Austin is gratefully acknowledged. Financial support was provided by the Australian Research Grants Scheme and the Research Trust Fund of the Australian Wool Corporation.

\section{REFERENCES}

ARNOLD, J. T. A. AND WhitTEN, M. J. 1975. Measurement of resistance in Lucilia cuprina larvae and absence of correlation between organophosphorus-resistance levels in larvae and adults. Entomol. Exp. Appl., 18, 180-186.

AYALA, F. J. AND CAMPBELL, C. A. 1974. Frequency-dependent selection. Ann. Rev. Ecol. System., 5, 115-138.

BROWN, A. W. A. AND PAL, R. 1971. Insecticide Resistance in Arthropods. W.H.O., Geneva.

CLARKE, B. 1975. The contribution of ecological genetics to evolutionary theory: detecting the direct effects of natural selection on particular polymorphic loci. Genetics, 79, 101 113.

Clarke, B. C. 1979. The evolution of genetic diversity. Proc. R. Soc. Lond. B., 205, 453-474.

COMINS, H. N. 1979. The management of pesticide resistance : models. In Genetics in Relation to Insect Management. M. A. Hoy and J. J. McKelvey Jr. (ed.). Rockefeller Foundation U.S.A., pp. 55-69.

CURTIS, C.F. 1981. Possible methods of inhibiting or reversing the evolution of insecticide resistance in mosquitoes. Pestic. Sci., 12, 557-564.

DOLAN, R. AND ROBERTSON, A. 1975. The effect of conditioning the medium in Drosophila, in relation to frequencydependent selection. Heredity, 35, 311-316.

EMLEN, J. M. 1985. The assessment of frequency-dependent and density-dependent influences on fitness in natural populations. Amer. Nat., 125, 507-520.

FOSTER, G. G., WHITTEN, M. J., KONOVALOV, C., ARNOLD, J. T. A. AND MAFFI, G. 1981. Autosomal genetic maps of the Australian sheep blowfly, Lucilia cuprina dorsalis R-D. (Diperta : Calliphoridae) and possible correlations with the linkage maps of Musca domestica L. and Drosophila melanogaster (Mg.). Genet. Res., 37, 55-69.
GEORGHiou, G. P. AND TAYLOR, C. E. 1976. Pesticide resistance as an evolutionary phenomenon. Proc. 15th Int. Congr. Entomol. Washington D.C. pp. 759-785.

HAJ-AHMAD, Y. AND HICKEY, D. A. 1982. A molecular explanation of frequency-dependent selection in Drosophila. Nature 299, 350-352.

HUANG, S. L., SINGH, M. AND KOJIMA, K. 1971. A study of frequency-dependent selection observed in the esterase- 6 locus of Drosophila melanogaster. Evolution, 6, 313-321.

HUGHES, P. B. 1981. Spectrum of cross resistance to insecticides in field samples of the primary sheep blowfly, Lucilia cuprina. Intern. J. Parasit., 11, 475-479.

HUGHES, P. B. AND DEVEONSHIRE, A. L. 1982. The biochemical basis of resistance to organophosphorus insecticides in the sheep blowfly, Lucilia cuprina. Pestic. Biochem. Physiol., 18, 289-297.

MANI, G. S. 1985. Evolution of resistance in the presence of two insecticides. Genetics, 109, 761-783.

MCKENZIE, J. A. 1983. The evolution of insecticide resistance: consequences for control programmes. In 2nd National Symposium on Sheep Blowfly and Flystrike in Sheep. Department of Agriculture, N.S.W. pp. 222-231.

MCKENZIE, J. A. 1984. Dieldrin and diazinon resistance in populations of the Australian sheep blowfly, Lucilia cuprina, from sheep-grazing areas and rubbish tips. Aust. J. Biol. Sci., 37, 367-374

MCKENZIE, J. A., DEARN, J. M. AND WHITTEN, M. J. 1980 Genetic basis of resistance to diazinon in Victorian populations of the Australian sheep blowfly, Lucilia cuprina. Aust. J. Biol. Sci., 33, 85-95.

MCKENZIE, J. A. AND WhitTEN, M. J. 1982. Selection for insecticide resistance in the Australian sheep blowfly, Lucilia cuprina. Experientia, 38, 84-85.

MCKENZIE, J. A. AND WHITTEN, M. J. 1984. Estimation of the relative viabilities of insecticide resistance genotypes of the Australian sheep blowfly, Lucilia cuprina. Aust. J. Biol. Sci., $37,45-52$.

MCKENZIE, J. A., WHITTEN, M. J. AND ADENA, M. A. 1982. The effect of genetic background on the fitness of diazinon resistance genotypes of the Australian sheep blowfly, Lucilia cuprina. Heredity, 49, 1-9.

PARSONS, P. A. 1971. Extreme-environment heterosis and genetic loads. Heredity, 26, 579-583.

PARSONS, P. A. 1983. The Evolutionary Biology of Colonizing Species. Cambridge University Press, New York

ROXBURGH, N. A. AND SHANAHAN, G. J. 1973. A method for the detection and measurement of insecticide resistance in larvae of Lucilia cuprina (Wied.) (Dipt., Calliphoridae). Bull. ent. Res., 63, 99-102.

TOS̀IĆ, M. AND AYALA, F. J. 1981. Density-dependent and frequency-dependent selection at the $\mathrm{Mdh}-2$ locus in Drosophila pseudoobscura. Genetics, 97, 679-701.

WAllaCE, B. 1968. Topics in Population Genetics. W. W. Norton, New York

WALLACE, B. 1975. Hard and soft selection revisited. Evolution, $29,465-473$

WHITTEN, M. J., DEARN, J. M. AND MCKENZIE, J. A. 1980 Field studies on insecticide resistance in the Australian sheep blowfly, Lucilia cuprina. Aust. J. Biol. Sci., 33, 725735

WHITTEN, M. J. AND MCKENZIE, J. A. 1982. The genetic basis for pesticide resistance. In Proc. 3rd Aust. Conf. Grassland Invertebrate Ecology. K. E. Lee (ed.). S. A. Govt. Printer, Adelaide, pp. 1-16.

WOOD, R. J. AND MANI, G. S. 1981. The effective dominance of resistance genes in relation to the evolution of resistance Pestic. Sci., 12, 573-581. 